\title{
Art as an Investment and Conspicuous Consumption Good
}

Benjamin R. Mandel

\section{Appendix}

In this appendix, the results of model simulations in section III B are compared with the measured moments of real art returns from previous empirical studies, and model simulations under alternate assumptions are discussed. A brief survey of recent studies reporting the levels, variance and inter-asset correlations for paintings or prints is summarized in the following tables:

\begin{tabular}{|c|c|c|c|c|c|c|c|}
\hline Author(s) & Period & Country & Art & Equity & Gov. Bond & $\begin{array}{l}\text { Corp. } \\
\text { Bond }\end{array}$ & T-Bill \\
\hline \multirow[t]{2}{*}{ Pesando \& Shum (2007) } & $1977-2004$ & US & $1.5 \%$ & $8.6 \%$ & $5.0 \%$ & & $1.9 \%$ \\
\hline & & & $17.1 \%$ & $22.6 \%$ & $18.8 \%$ & & $2.7 \%$ \\
\hline \multirow[t]{2}{*}{ Mei \& Moses (2002) } & 1900-1999 & US & $5.2 \%$ & $6.7 \%$ & $1.4 \%$ & $2.0 \%$ & $1.1 \%$ \\
\hline & & & $35.5 \%$ & $19.8 \%$ & $8.6 \%$ & $8.4 \%$ & $4.9 \%$ \\
\hline \multirow[t]{2}{*}{ Pesando (1993) } & 1977-1999 & US & $1.5 \%$ & $8.1 \%$ & $2.5 \%$ & & $2.2 \%$ \\
\hline & & & $19.9 \%$ & $22.5 \%$ & $21.8 \%$ & & $3.4 \%$ \\
\hline \multirow[t]{2}{*}{ Goetzmann (1993) } & $1850-1986$ & UK & $3.8 \%$ & $0.2 \%$ & $1.7 \%$ & & \\
\hline & & & $65.0 \%$ & $26.0 \%$ & $21.5 \%$ & & \\
\hline
\end{tabular}

Correlation of Art Returns with Equity and Debt

\begin{tabular}{|c|c|c|c|c|c|c|}
\hline Author(s) & Period & Country & Equity & Gov. Bond & $\begin{array}{l}\text { Corp. } \\
\text { Bond }\end{array}$ & T-Bill \\
\hline Pesando \& Shum (2007) & $\overline{1977-2004}$ & US & 0.21 & -0.09 & & -0.27 \\
\hline Mei \& Moses (2002) & 1900-1999 & US & 0.04 & -0.15 & -0.10 & -0.03 \\
\hline Pesando (1993) & 1977-1999 & US & 0.30 & -0.10 & & -0.21 \\
\hline Goetzmann (1993) & $1900-1986$ & UK & 0.79 & 0.53 & & \\
\hline
\end{tabular}

Three patterns in art return estimates emerge from these studies:

1. The level of real art returns is relatively low. The robustness and qualifications associated with this observation are discussed at length in sections I and II and it is easily reproduced by the model simulations presented in table 4: in all cases equity returns are higher than art returns, and in some cases art returns exceed bond returns. The one exception to this pattern in the data is Goetzmann (1993) in which art returns are higher than London Stock Exchange returns for the period 1850-1986, though there it is not the art return measure that is atypically low, but rather that of equity (which is also lower than the return of Consols). In the model, art returns are increasing in the coefficient of relative risk aversion, the endowment growth rate and the endowment lag covariance. It is not possible to reproduce art return levels of greater than 3 percent by increasing the level of risk aversion alone; at least, that 
is not possible while maintaining an intermediate degree of risk aversion. However, 3.8 percent in Goetzmann (1993) and 5.2 percent in Mei and Moses (2002) can be obtained by jointly increasing $\left(\alpha=8 ; E\left[\gamma_{t}\right]=1.035\right)$ and $\left(\alpha=8.75 ; E\left[\gamma_{t}\right]=1.05\right)$, respectively, while maintaining a zero art risk premium. Alternatively, the levels in Goetzmann (1993) and a zero risk premium can be replicated by decreasing the endowment lag covariance to $\operatorname{cov}\left[\gamma_{t}, \gamma_{t-1}\right]=-0.65 .^{1}$ Thus, settings with simultaneously high endowment growth and risk aversion or a high frequency of switching between states are consistent with high art returns and a low art risk premium.

2. The variance of real art returns is at least as high as equity returns and higher than bond returns. Across studies above, the variance of art returns is unambiguously higher than for corporate bonds and T-bills and is either the same or higher than for government bond returns. In table 4, the variance of art returns is about that same as for equity returns and both exceed that of bonds. The predicted variance of asset returns is sensitive to the calibration of the endowment process. In order to match the observed standard deviation of equity returns of 20 percent and maintain risk aversion of $\alpha>1$, the standard deviation of the endowment itself has to be at least 20 percent. Alternatively, all else equal, the endowment lag covariance could be decreased to $\operatorname{cov}\left[\gamma_{t}, \gamma_{t-1}\right]=-0.6$. Intuitively, more volatile states, with high probability of switching, are consistent with high variance in asset returns. The model as specified is not particularly well-equipped to generate a different variance of returns between art and equity, as in Mei and Moses (2002) and Goetzmann (1993), though this may simply reflect the imposed separability of art in utility. Moreover, the measured variance of art returns may itself be sensitive to data gathering techniques and related limitations.

3. Art returns are positively correlated with equity returns and negatively correlated with bond returns. In all cases, the measured correlation of art and equity returns is positive. With the exception of Goetzmann (1993), equity and bond returns are negatively correlated. Model predictions are consistent with these findings as discussed in section III B, though the stylized 3-state economy with only one art asset yields stronger correlations than actually observed (i.e., for the baseline case, $\operatorname{Corr}($ Art, Bond $)=-0.91$ and $\operatorname{Corr}($ Art, Equity $)=0.99)$. Again, the particular form of utility may be imposing this strong similarity between equity and art. For example, settings in which art has a different coefficient of relative risk aversion than the consumption good may diminish the comovement of their respective asset prices.

\footnotetext{
${ }^{1}$ Replicating 5.2 percent in Mei and Moses (2002) with this calibration assumption alone would lead to an unstable transition matrix.
} 


\section{References}

[1] Goetzmann, William N. 1993. "Accounting for Taste: Art and Financial Markets over Three Centuries." American Economic Review, 83(5): 1370-1376.

[2] Mei, Jianping and Michael Moses. 2002. "Art as an Investment and the Underperformance of Masterpieces." American Economic Review, 92(5): 1656-1668.

[3] Pesando, James E. 1993. "Art as an Investment: The Market for Modern Prints." American Economic Review, 83(5): 1075-1089.

[4] Pesando, James E. and Pauline M. Shum. 2007. "The Auction Market for Modern Prints: Confirmations, Contradictions, and New Puzzles." Economic Inquiry, 46(2): 149-159. 